Document downloaded from:

http://hdl.handle.net/10251/94477

This paper must be cited as:

Bloem, C.; Salvador Moya, MD.; Amigó, V.; Busquets Mataix, DJ. (2004). Microstructural change of the HAZ in an MIG welded bond on an AA7020 aluminium alloy: stress corrosion crack growth rate in dissimilar metal welds. Welding International. 18(7):538-542. doi:10.1533/wint.2004.3287

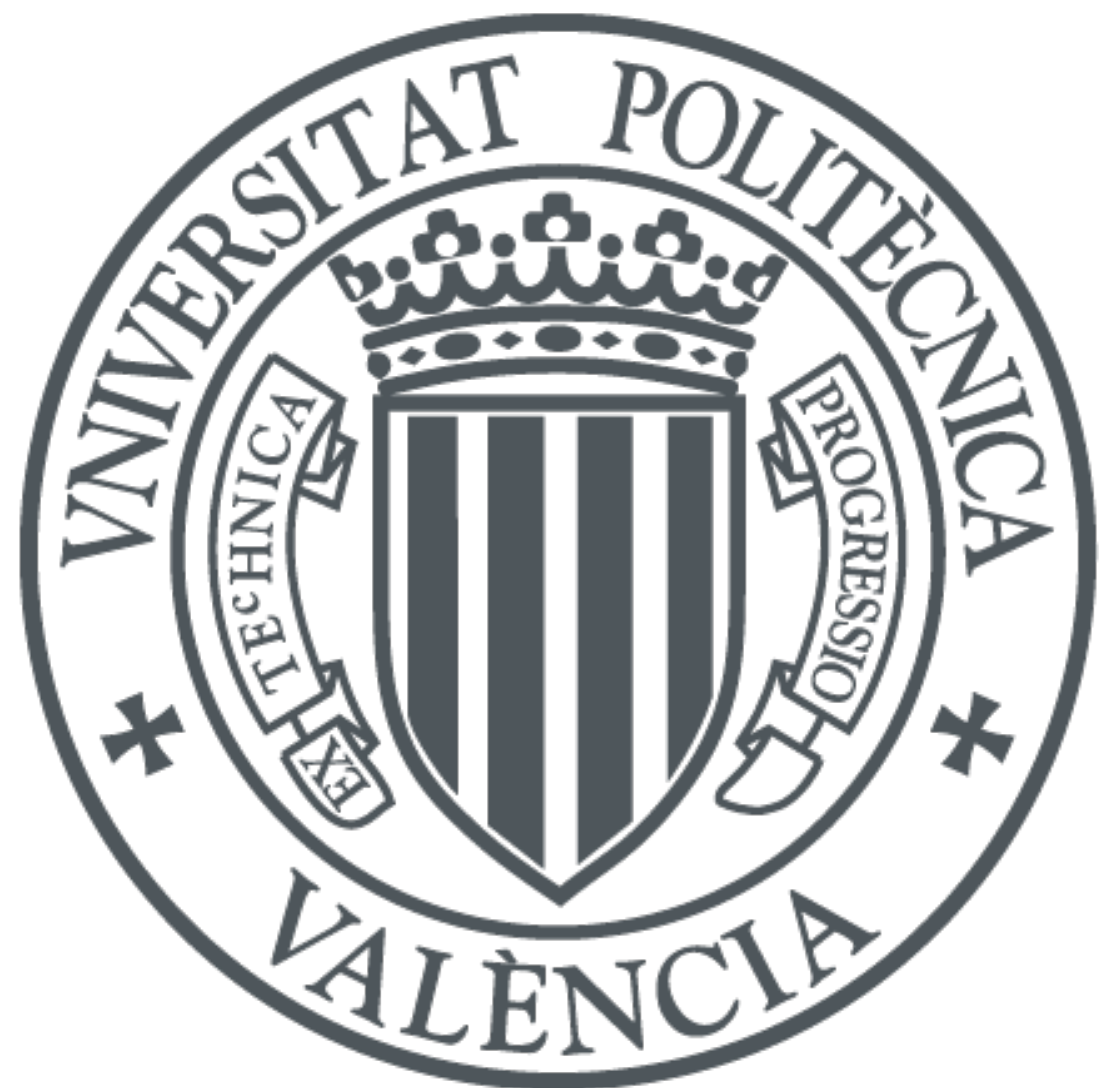

The final publication is available at

http://doi.org/10.1533/wint.2004.3287

Copyright Taylor \& Francis

Additional Information 


\title{
Microstructural change of the HAZ in an MIG welded bond on an AA7020 aluminium alloy: stress corrosion crack growth rate in dissimilar metal welds
}

\author{
C.A. BLOEM
}

Department of Technology and Design, School of Mechanical Engineering, Universidad de Los Andes de Ingeniería

\author{
M.D. SALVADOR, V. AMIGÓ and D. BUSQUETS
}

Department of Mechanical Engineering and Materials, ETSII, Universidad Politécnica de Valencia

\section{Introduction}

AW 7XXX-series aluminium alloys with mid-range performance qualities are used ever more frequently in the manufacturing of welded structures, due to the industrial and technological development of different welding methods that render the use of such structures ever more competitive. At the same time, this requires greater knowledge both of the welded bond and of the welding process or of microstructural change throughout the HAZ, in welds of this type.

Many researchers have undertaken studies into the mechanical behaviour of the welded bond,1,2 others have devoted their attentions to metallurgical phenomena, whether concerning phenomena inherent to the area immediately surrounding the weld interface or concerning models or simulations of the welded structure;3,4 in addition, there are those who have made comparisons between different welding methods2 or who have dedicated their time to post-welding treatments. 5 However, very few researchers have devoted their attentions to studying microstructural change throughout the HAZ on welded test pieces.

\section{Materials}

The base material used to create the welded bonds came from an AA7020 aluminium alloy sheet obtained through lamination. Its dimensions were $1000 \times 1000 \times 5 \mathrm{~mm}$. As recommended in various literature,6,7 the filler material used for the welded bond belonged to the Al-Mg family, namely AA5356 in the form of wire $1.2 \mathrm{~mm}$ in diameter. The protective gas used was a 75\% Argon / 25\% Helium blend at a flow of 12 $\mathrm{l} / \mathrm{min}$.

The chemical composition of the base and filler materials are shown in Table 1.

Table 1 Chemical composition (\% mass)

\begin{tabular}{|c|c|c|c|c|c|c|}
\hline & $\mathrm{Zn}$ & $\mathrm{Mg}$ & $\mathrm{Si}$ & $\mathrm{Cr}$ & $\mathrm{Mn}$ & $\mathrm{Fe}$ \\
\hline Base material AA 7020 & 5.1 & 1.2 & 0.2 & 0.3 & 0.2 & 0.3 \\
\hline Filler AA 5356 & 0.1 & 5.0 & - & 0.1 & 0.2 & - \\
\hline
\end{tabular}

\section{Experimental procedure}

The welding procedure employed was MIG DC, given its widespread usage and its relatively low cost. Welds on sheets were created, the dimensions of which were $350 \times$ $150 \times 5 \mathrm{~mm}$, carrying out welding along the longest dimension perpendicularly in the direction of the lamination. To start with the sheets were cut using sheet metal cutters 
and the surfaces that were going to be welded milled. The sheets were held in place from the rear using a pair of rests, with the aim of minimizing the distortion generated during welding.

The weld was created in two passes, welding being preceded by mechanical cleaning and, between the first and second passes, by means of a grinding wheel and a stainless steel brush.

The welding parameters are shown in Table 2.

Table 2 Welding parameters

\begin{tabular}{|c|c|c|c|c|}
\hline & Voltage (V) & Current (Amp) & $\begin{array}{c}\text { Velocity } \\
(\mathrm{mm} / \mathrm{min})\end{array}$ & EBA (KJ/cm) \\
\hline 1st pass & 21.0 & 140 & 525 & 5.6 \\
\hline 2nd pass & 21.0 & 140 & 382 & 7.7 \\
\hline
\end{tabular}

Microscopic observation

TEM microscopic observations were carried out throughout the HAZ, approximately every $2 \mathrm{~mm}$, up to a distance of $40 \mathrm{~mm}$ from the base metal / weld bead interface. The disks $3 \mathrm{~mm}$ in diameter used for TEM observation were taken from small transversal sheets measuring $5 \times 5 \mathrm{~mm} \times 150-200 \mu \mathrm{m}$. As can be seen in Fig. 1, they were cut adjacent to those sheets used as a source for Differential Scanning Calorimetry (DSC), using a diamond-studded wire $0.19 \mathrm{~mm}$ in diameter.

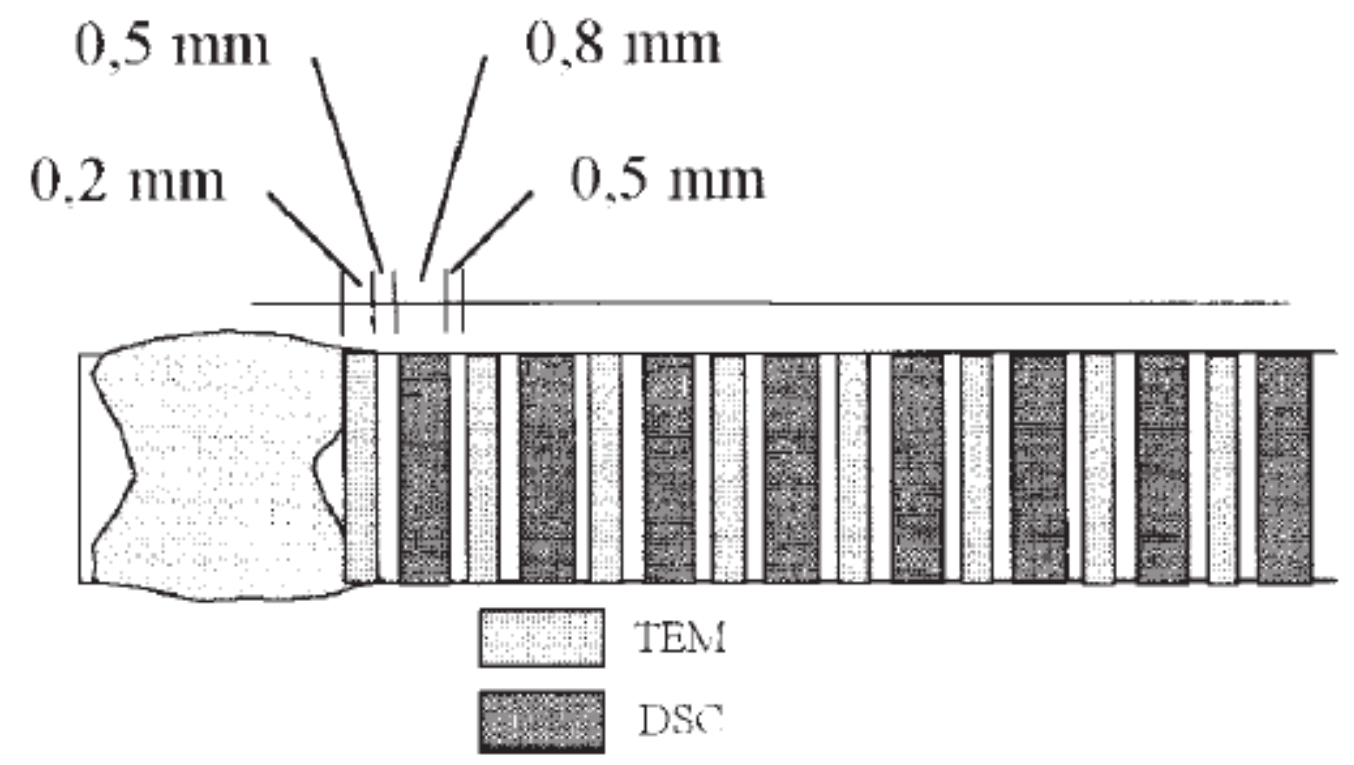

Fig 1 Cutting schedule of TEM and DSC samples.

Disks $3 \mathrm{~mm}$ in diameter were punched out from the sheets obtained and these were then pared down to a thickness of $100 \mathrm{~mm}$ through mechanical polishing. Tenupol 3 equipment was then used electrolytically on these disks until perforation was achieved, using a solution comprising $20 \%$ nitric acid in ethanol at a temperature of $-20{ }^{\circ} \mathrm{C}$.

TEM observation was carried out using a Phillips EM 400 miscroscope in bright-field at different magnifications, in order to be able to evaluate the quality and quantity of the 
precipitates existing throughout the HAZ. The results analysis includes a sample of the micrographs obtained.

Differential Scanning Calorimetry

Differential Scanning Calorimetry (DSC) was applied systematically throughout the $\mathrm{HAZ}$, in order to analyse the change in the precipitates of the latter. The tests were carried out up to a distance of more than $40 \mathrm{~mm}$ from the base metal / bead interface.

The samples for testing were taken from positions adjacent to those that were used for TEM microscopy, as depicted in Fig. 1. The test pieces, which weighed around $30 \mathrm{~g}$ each and had dimensions of approximately $5 \times 5 \times 0.8 \mathrm{~mm}$, were kept in the aluminium sample holder of the calorimeter.

The equipment used was a Perkin Elmer DSC 7, with a heating velocity of $20^{\circ} \mathrm{C} / \mathrm{min}$ from $35^{\circ}$ to $410^{\circ}$. The tests were carried out using a standard $99.998 \%$ aluminium sample, ${ }^{8,9}$ the protective gas used was Argon at $25 \mathrm{~cm}^{3} / \mathrm{min}$; in addition, a base line was used in order to improve the definition of the results obtained.

\section{Analysis of findings}

Differential Scanning Calorimetry

In order to carry out DSC analysis, one needs to define the precipitation sequence of such alloys, as well as the temperature ranges at which transformations take place. For 7XXX-series alloys, the widely accepted precipitation sequence, discussed in the literature9,10 is as follows:

$\alpha_{\mathrm{SS}} \rightarrow \alpha_{1}+\mathrm{GP} \rightarrow \alpha_{2}+\eta^{\prime} \rightarrow \alpha_{\mathrm{eq}}+\eta$

Next one defines the temperature ranges for the precipitation-dissolution process. These are based upon data from the literature, ${ }^{4,8,9}$ where three clearly defined zones are observed.

The first, an endothermic zone (troughs) that stretches approximately from $100{ }^{\circ} \mathrm{C}$ to $190^{\circ} \mathrm{C}$ and corresponds to the dissolution of Guinier-Preston (GP) Zones.

The second, an exothermic zone (peaks) that stretches from $200{ }^{\circ} \mathrm{C}$ to $290{ }^{\circ} \mathrm{C}$ and corresponds to the formation of the metastable phase $\eta$ '.

The third is a zone in which three different phenomena take place almost simultaneously: phase $\eta$ ' dissolution, phase $\eta$ formation and the dissolution of the latter.

The different DSC calorimetric tests are depicted in Fig. 2 and are shown set out at intervals according to their distance from the base metal / bead interface, so as to facilitate analysis. A small scale is shown on the ordinates axis, which indicates the magnitude of energy exchanges. The peaks or crests indicate exothermic reactions or the dissolution of precipitates and the troughs represent endothermic reactions or the formation of precipitates. 


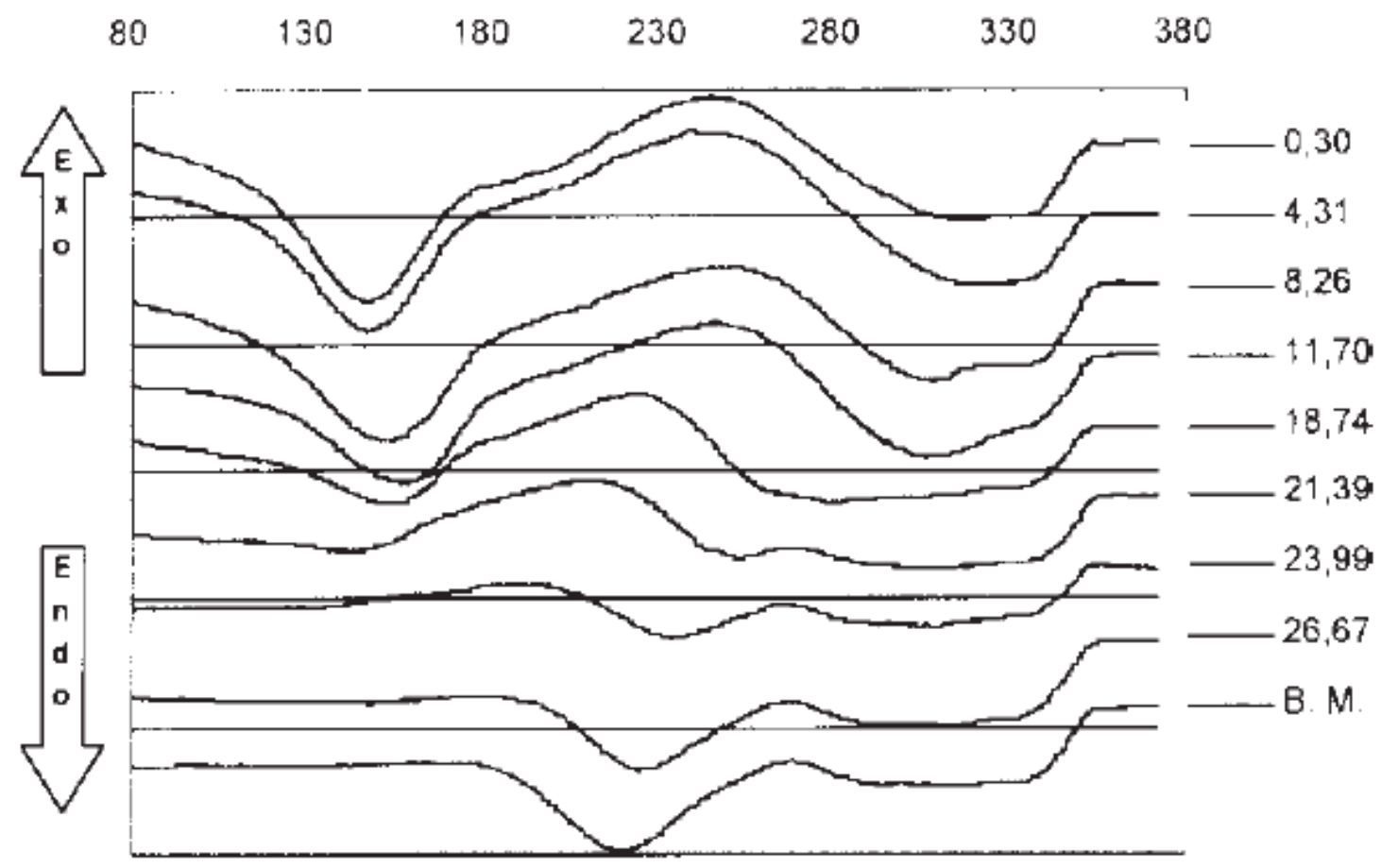

Fig 2 DSC scanning throughout the HAZ.

One can see from Fig. 2, in the region corresponding to GP dissolution (100-190 $\left.{ }^{\circ} \mathrm{C}\right)$, how, moving further away from the base metal / bead interface, there is a reduction in energy and a shift from the trough towards higher temperatures, indicating that, during welding in that region, up to $18-20 \mathrm{~mm}$ total or partial dissolution of precipitates may take place, with a precipitation of those structures of the GP variety. The shift from the trough towards higher temperatures indicates that the precipitate is more stable, in line with the more homogenous distribution of precipitates at measurements that take us further away from the interface.

On the other hand, the lack of GPs beyond the $20 \mathrm{~mm}$ mark clearly indicates that, during welding, this region has only suffered from overaging and there has been no dissolution of precipitates, as observed with TEM.

In regards to the second and third regions, those relating to $h^{\prime}$ precipitation, $h^{\prime}$ dissolution and $h$ formation, given that these phenomena are quite complex since they include the dissolved solute of the GPs and the remainder of the mould, another type of analysis is required in order to allow one to discuss them. However, it can be noted how, as one moves further away from the interface, the temperature of the $\eta$ ' formation peak (200-290 ${ }^{\circ} \mathrm{C}$ ) moves towards lower temperatures, a product of the stability of GPtype structures, which tend to be transformed directly into $\eta '$ '.

Clearly, the best means of checking these changes through TEM would be to carry out the tests on the same sample, even though it is true that, as this was not possible, the samples were obtained by alternative means (Fig. 2), meaning that, for every two DSC samples there is always a TEM sample and, likewise, for every two TEM samples, there is always a sample for DSC. This pattern allows us to have at our disposal samples for the length of the bead. These provide us with additional indications as to changes in precipitates, both in regards to their dissolution and formation mechanisms and in regards to their quantity and size. To this end, an additional study was carried out by 
means of transmission electron microscopy so as to allow us to track the changes brought about through DSC.

TEM microscopic observation

Figures 3 to 8 show a range of different microscopic observations carried out throughout the HAZ, in which one can perceive a substantial variation in the precipitates present.

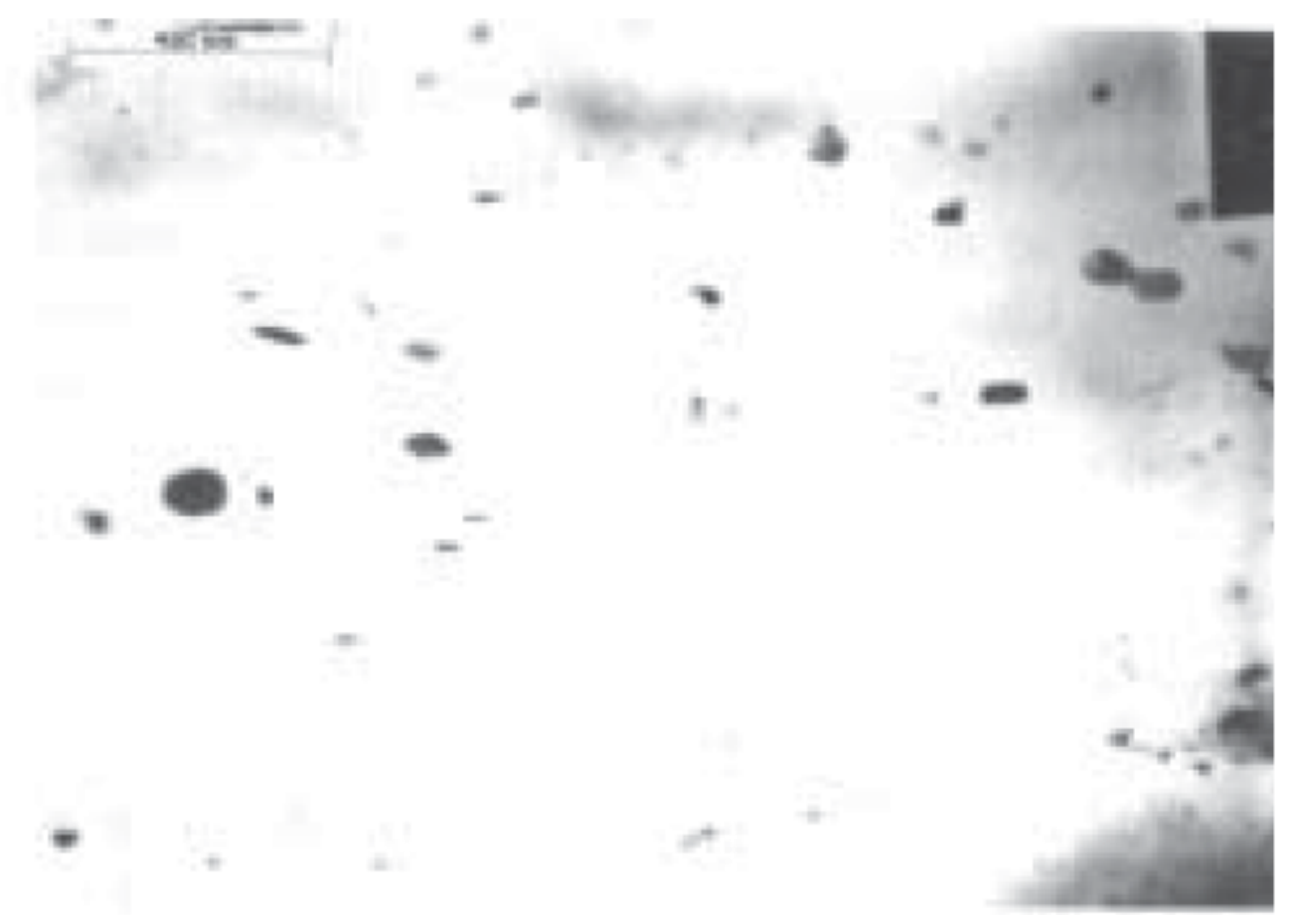

Fig 3 Precipitates in HAZ at a distance of $0.6 \mathrm{~mm}$ from the interface $(\times 21500)$.

In the Fig. 3 photograph, corresponding to a distance of $0.6 \mathrm{~mm}$ from the base metal / bead interface, within the HAZ one can see how the level of precipitation is heterogeneous with regard to morphology and size, as it combines a spheroid-type precipitation and another more acicular form, although these shapes are those found, in various sizes and to a greater or lesser degree, in all the sections studied. This is a result of the heat variations generated during the welding process, which it must be stressed is a process comprising two passes. This low density of precipitates, described by various authors, ${ }^{3,4}$ indicates that total dissolution of precipitates takes place in this zone, a product of the heat gain during welding. 


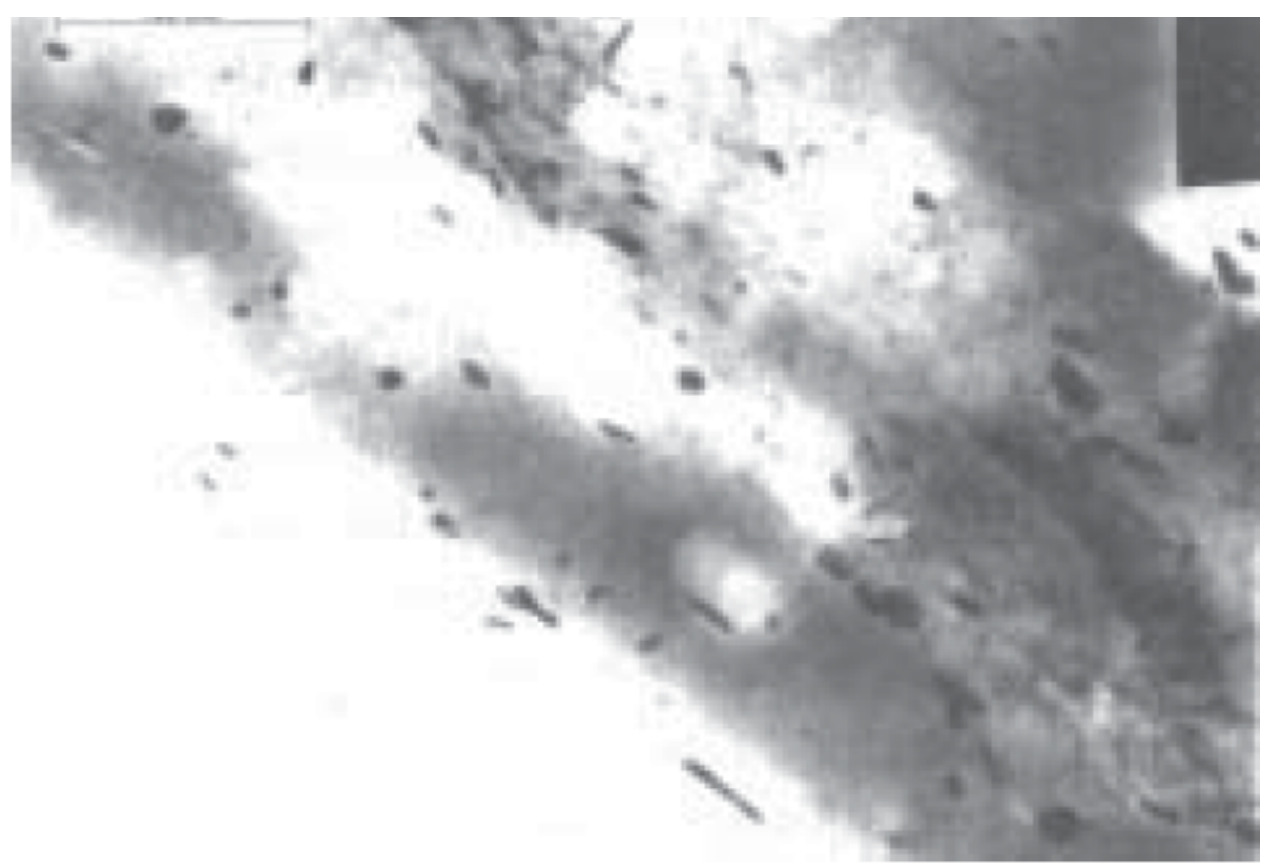

Fig 4 Precipitates in HAZ at a distance of $3.2 \mathrm{~mm}$ from the interface $(\times 21500)$.

In Fig. 4, corresponding to a distance of $3.2 \mathrm{~mm}$ from the interface, one can see an increase in the difference in the size of precipitates compared to the observations made at a distance of $0.6 \mathrm{~mm}$ from the interface. In addition, the distribution of the precipitates is very diverse and one can perceive zones with very low precipitation and even precipitation-free zones. The tests carried out on these samples showed contents of up to $2.75 \%$ semicoherent particles, $\eta$ ', at $3.2 \mathrm{~mm}$, compared with a content of $1.34 \%$ from that particular phase at $0.6 \mathrm{~mm}$. from the interface. The composition of these precipitates was obtained by means of EDX, but it was not possible to offer an accurate estimate as the composition included a very high content in aluminium from the mould, although the proportion of the latter is very close to $\mathrm{MgZn}_{2}$.

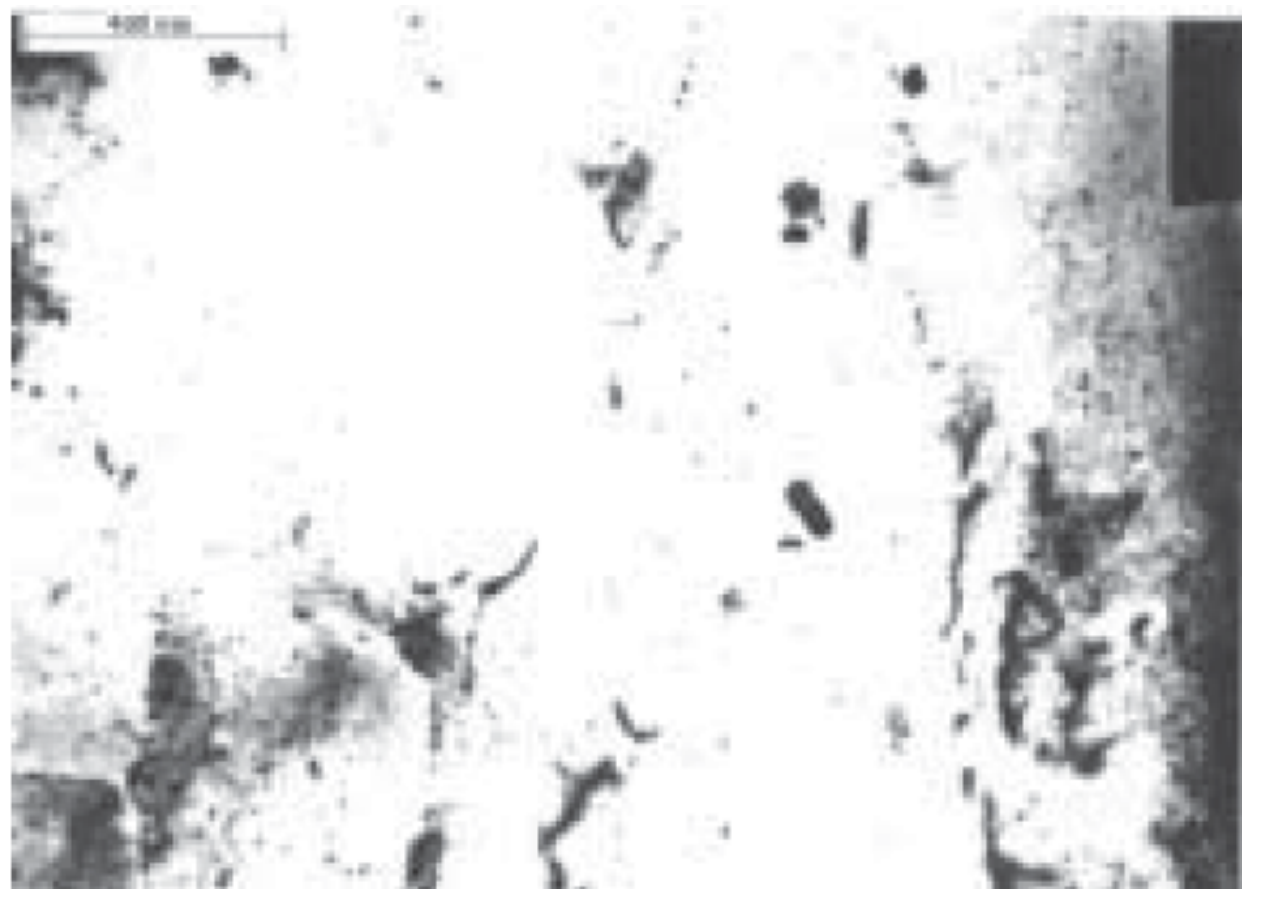

Fig 5 Precipitates in HAZ at a distance of $8.5 \mathrm{~mm}$ from the interface $(\times 21500)$. 
In Fig. 5, corresponding to a distance of $8.5 \mathrm{~mm}$. from the interface, the situation is very similar to that in the previous case, in regards to the size and shape of precipitates.

However, the size of these spheroid and acicular precipitates is slightly smaller than those observed at $3.2 \mathrm{~mm}$, which appears to indicate that the temperature reached during welding in this region was sufficiently high to dissolve and homogenise the structure, but the remaining heat only served to generate precipitation of a smaller size than in the previous case, in line with published findings.3,10 Similarly, one can see from the DSC graphs (Fig. 2) the great similarity in the curves up to $11.70 \mathrm{~mm}$, confirming the similarity of the precipitation and dissolution mechanisms that take effect at these distances from the interface of the weld beads.

In fact, very close to this distance, at $11.2 \mathrm{~mm}$, as can be perceived in Fig. 6, one sees a slightly more coarse precipitation of more stable MgZn2 precipitates. Nonetheless, one also sees very fine, sparse precipitation. One of the few differences discovered during DSC analysis is rooted in the appearance of a small peak of stable precipitate formation, $\eta$, at a distance of $8.3 \mathrm{~mm}$, while this is imperceptible at $11.70 \mathrm{~mm}$. The reason for coarser precipitation may be that, during welding, the temperature reached did not manage to dissolve all the precipitates present and that, with the remaining heat, this meant that those precipitates that did not dissolve completely grew and that a fine precipitation was generated.

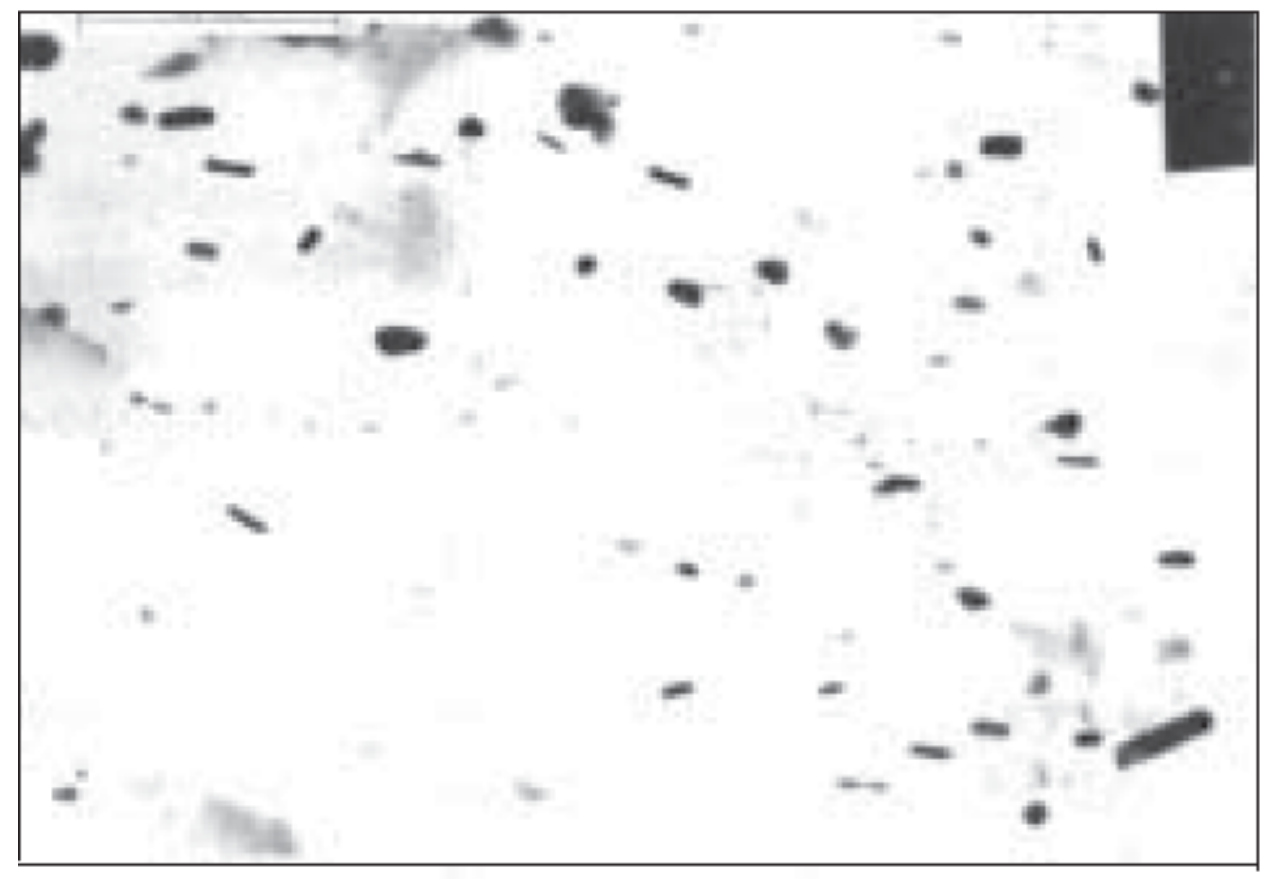

Fig 6 Precipitates in HAZ at a distance of $11.2 \mathrm{~mm}$ from the interface $(\times 21500)$.

However, at greater distances, one can perceive a substantial difference in the DSC graphs, where the peaks corresponding to the formation and dissolution of GPs practically disappear, alongside an ever-increasing shift from the peak corresponding to the formation of precipitates, $\eta{ }^{\prime}$. At a distance of $17.7 \mathrm{~mm}$ (Fig. 7), one observes less formation of precipitates, although a fine distribution of spheroid precipitates, $h$ ', persists. This probably indicates that, during welding, even in this region, partial dissolution, coarsening and precipitation took place. 


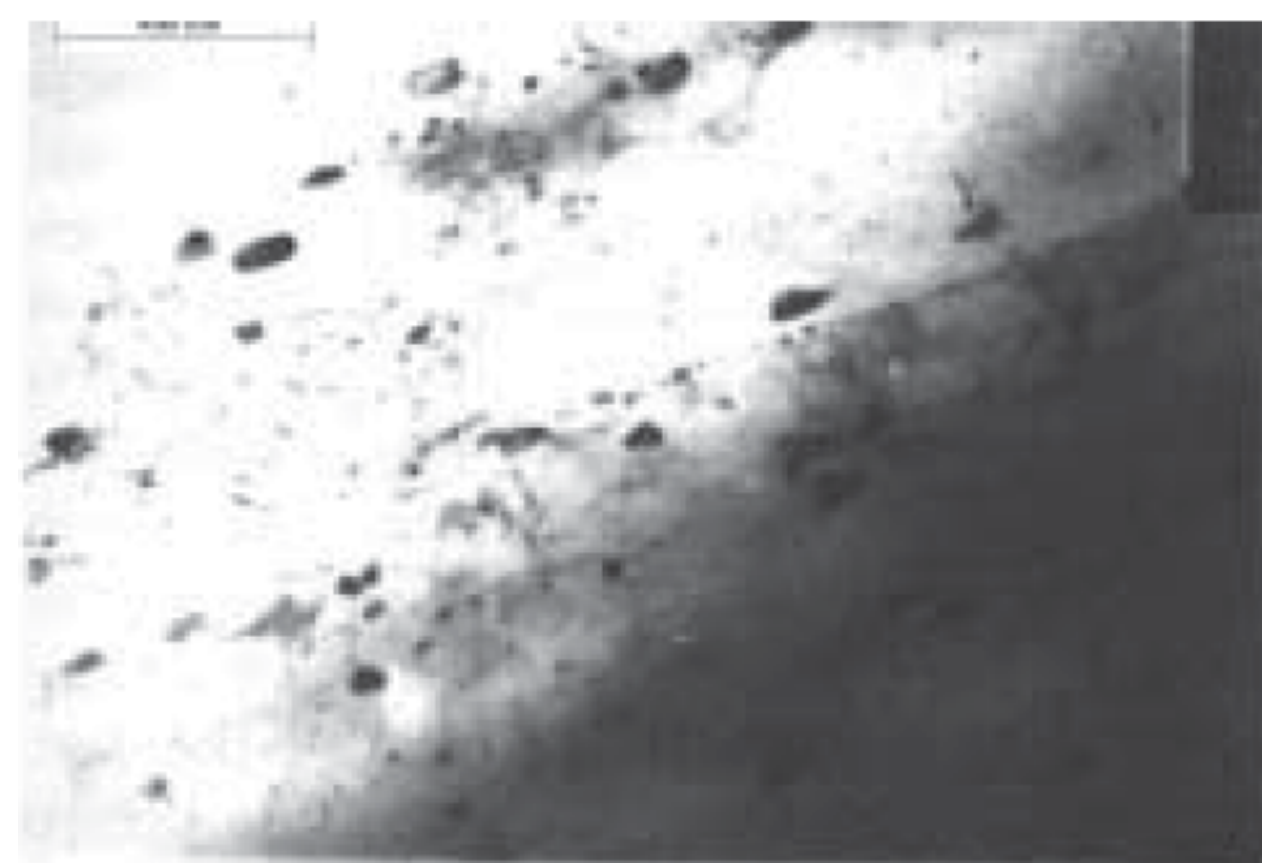

Fig 7 Precipitates in HAZ at a distance of $17.7 \mathrm{~mm}$ from the interface $(\times 21500)$.

If one examines Fig. 8, which corresponds to a distance of $25.6 \mathrm{~mm}$, one can see the appearance of the typical mosaic structure corresponding to what would be the base metal, with fine type- $\eta$ ' precipitates absent, although we still see a smaller number of coarser precipitates that are larger in size. The presence of the mosaic-type structure shows that, during the welding process, the temperature reached was insufficient to recrystallise this region, from which it can be inferred that, during welding, the only thing that happened in this region was a growth in the precipitates. We produce the same finding when we compare the DSC graphs corresponding to a distance of 26.6 $\mathrm{mm}$. and the base metal graph, which are almost the same and are different from those corresponding to shorter distances from the interface.

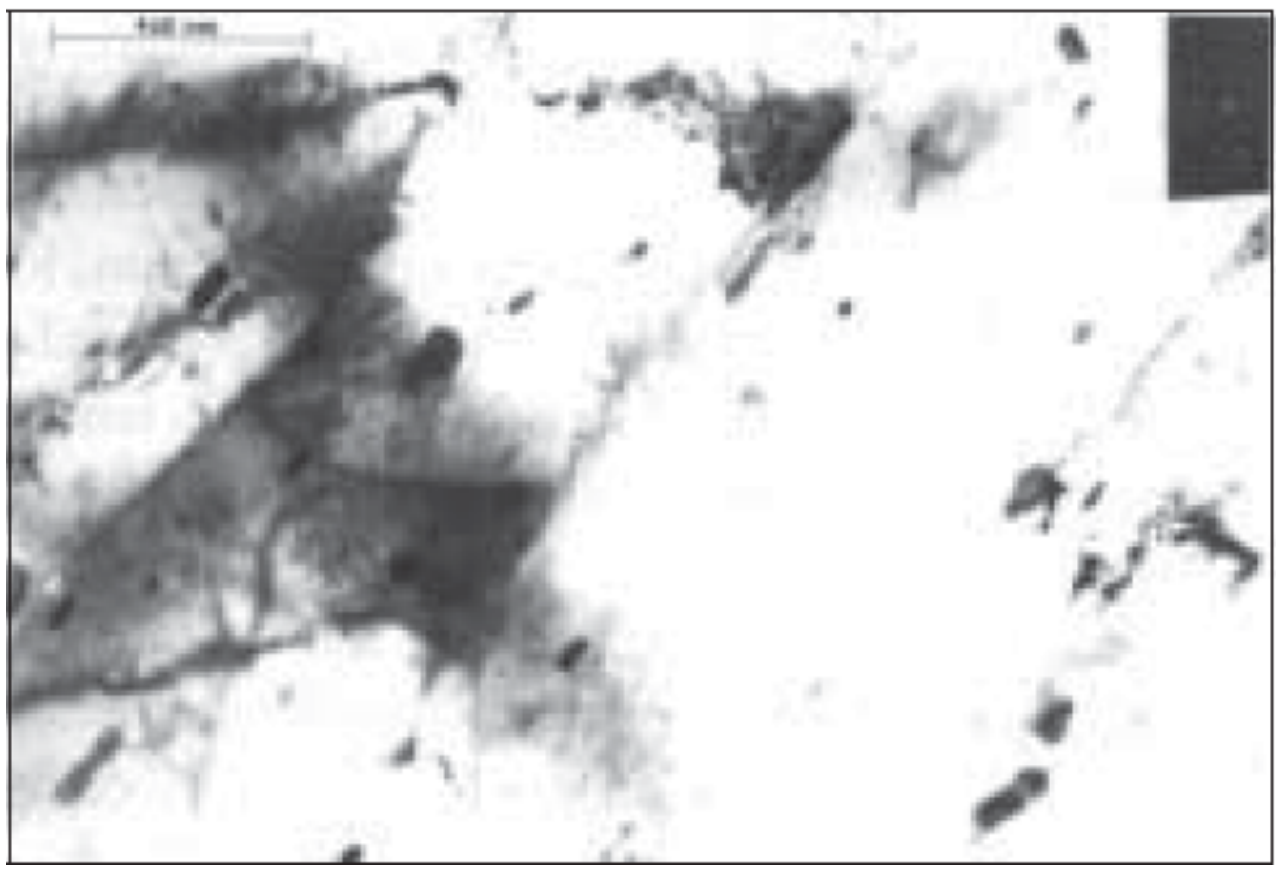

Fig 8 Precipitates in HAZ at a distance of $25.6 \mathrm{~mm}$ from the interface $(\times 21500)$. 
To sum up, it can be assumed that, due to the welding process, three clearly defined zones are generated in the HAZ: the first, from the base metal / bead interface to 7-12 $\mathrm{mm}$, where the principal GP and $h^{\prime}$ formation and solution phenomena take place; the second, from that $12 \mathrm{~mm}$ mark to approximately $20 \mathrm{~mm}$, where the $\eta^{\prime}$ precipitate formation temperature gradually falls; the third and final zone, from that $20 \mathrm{~mm}$ mark outwards, where phase $h$ stabilizes with a greater presence of stable $\mathrm{MgZn}_{2}$ precipitates.

\section{Conclusions}

The changes in precipitates throughout the HAZ were evaluated using Transmission Electron Microscopy and Differential Scanning Calorimetry, which proved to be crucial tools for observing the precipitates present and the formation of others, when the solute is submitted to further heat treatments using DSC.

The $\eta$ ' and $\eta$ formation processes are complex phenomena as they involve both the solute from the GPs and the solute remaining on the mould. The greater stability of GPs means that the $\eta$ ' formation temperature is lower. The level of $\eta$ ' precipitation is substantially more complex due to the overlapping of peaks in the DSC record, creating a need to use other techniques to support the latter.

Three completely different zones can be observed within the HAZ: the first is a zone of total dissolution and precipitation, at distances close to the interface with the weld bead; the second is a zone of partial dissolution, precipitation and overaging; while the third is based upon overaging and, therefore, the dissolution and precipitation are essentially non-existent.

\section{References}

1 V Malin: Weld Res Supplement, 1995 305-318.

2 J M Gómez de Salazar et al: Rev Metal Madrid 199834 276-280.

3 T Ma Den Ouden: Mater Sci Eng 1999 A266 198-204.

4 N Ryum: Z. Metalkd 197566 377-388.

5 D Busquets: Estudio del comportamiento a fatiga de uniones soldadas de aluminio de alta resistencia para su empleo en la industria del transporte, UPV, Spain, 1987.

6 American Society for Metals, Specialty Handbook Aluminium and Aluminium Alloys ASM International, 1993.

7 Alubook:http://www.alu-info.dk/html/alulib/modul/albook40.htm, Feb 2001.

8 C García Cordovilla and E Louis: Metall Trans 1990 A21 2.277-2.280.

9 C Bloèm et al: Rev Cienc Ing 2000 21-3.

10 B J Bjorneklett et al: Sci Technol Weld Joining 19994 (3) 